\title{
Virtuous Construal: In Defense of Silencing
}

\begin{abstract}
Over several articles, John McDowell sketches an analogy between virtue and perception, whereby the virtuous person sees situations in a distinctive way, a way that explains her virtuous behavior. Central to this view is his notion of silencing, a psychological phenomenon in which certain considerations fail to operate as reasons in a virtuous person's practical reasoning. Despite its influence on many prominent virtue ethicists, McDowell's 'silencing view' has been criticized as psychologically unrealistic. In this article, I defend a silencing view of practical reasoning. I argue that the phenomenon of silencing has a narrower scope than is typically acknowledged. As a result, the view does not require the virtuous to be detached, unfeeling, or unpalatably stoic. Furthermore, I offer a psychologically plausible interpretation of McDowell's claim that the virtuous see situations in a distinctive sort of way. The salient fact at which the virtuous arrive in their view of a situation should be understood, I argue, in terms of subjective construal.
\end{abstract}

KEYWORDS: silencing, John McDowell, practical reasoning, virtue

The contemporary literature presents two competing models of how virtuous individuals reason practically. On the one hand is what Anne Margaret Baxley calls 'the overriding view', which holds that a virtuous individual can acknowledge competing reasons for acting but that some considerations are overridden or outweighed when virtue demands (2007). On this view, for example, a virtuous individual can accept that the deliciousness of the chocolate cake is a reason for her to eat another piece, even though that reason is overridden-perhaps quite effortlessly-by concerns of fairness and politeness when taking another piece would, say, deprive her dinner guests of a fair share. The alternative to the overriding view is what, following Baxley, I call 'the silencing view', most notably advanced by John McDowell in a series of articles in which he draws an analogy between virtue and perception, whereby the virtuous person sees situations in a distinctive way, a way that explains her virtuous behavior (I998). On the silencing view, in situations in which there is a clear requirement of virtue, considerations in favor of acting contrary to virtue are not outweighed or overridden, but rather silenced altogether; in other words, they fail to operate as reasons at all. The

Thanks to Rosalind Hursthouse, John Greenwood, Dan Mailick, John McDowell, Jonathan McKeown-Green, Annalisa Paese, Jesse Prinz, Iakovos Vasiliou, and the anonymous reviewers from this journal for comments on earlier versions of this article. Final revisions of this article were supported by a summer stipend from the Seton Hall University Research Council. 
silencing view has faced substantial criticism. Even those who are sympathetic to the view seem to think that there is something wrong about the notion that considerations such as one's life, health, or loved ones that, in many or even most circumstances might constitute reasons for action, can be altogether silenced (see, e.g., Hursthouse 1999: I82-183). As a result, the overriding view appears dominant in the literature.

In this article, I defend a silencing view of practical reasoning. I begin by presenting McDowell's view and some criticisms of it. I argue that the silencing view is not as vulnerable to these criticisms as it might first appear. The view does not, I contend, require the virtuous to be detached, unfeeling, or unpalatably stoic. Furthermore, I suggest that the psychological phenomenon of silencing itself may not be exclusive to the virtuous. Finally, I offer what I argue is a psychologically plausible interpretation of McDowell's claim that the virtuous see situations in a distinctive sort of way. Despite its idealism, the picture of the virtuous that we get on the account that I develop here is a decidedly human one.

\section{McDowell's Account of Silencing}

McDowell likens virtue to a perceptual capacity; the virtuous, he claims, see situations in which there is a clear requirement of virtue in a distinctive sort of way. Briefly, his description of the virtuous person's psychology is as follows: knowledge of how one ought to live combines with knowledge of the particulars of a situation to produce a view of that situation in which one fact about the situation is seen as salient (1998: 65-69). This salient fact then 'meshes' (67) with a particular concern of the individual to yield action. Let us examine this picture in more detail.

McDowell is a particularist; although the extent of his particularism is controversial (see, e.g., Hursthouse I999: 57-58), he clearly holds that ethics cannot be codified into a set of universal principles. Consistent with this particularist position, McDowell is explicit that 'knowledge of how one ought to live' is not merely propositional knowledge and certainly not knowledge of universal principles (I998: 73). Rather, it is one's moral outlook, 'a specific determination of one's practical rationality' (I998: 58 ) that has both evaluative and affective aspects. Clearly, McDowell is using 'knowledge' here in an uncommon way. Because the virtuous, by definition, have the correct moral outlook, we can think of them, McDowell suggests, as having knowledge.

A virtuous person's knowledge of the particulars of a situation includes 'all' facts that could be, as McDowell puts it, 'potentially reason-yielding' (I998: 69n3 I). One may worry that McDowell is expecting omniscience from the virtuous here with his inclusion of all facts, but the point is better understood in light of his claim that the virtuous arrive at a view of the situation in which a single fact is seen as salient. 'All facts' emphasizes that virtue is not a matter of putting on blinders, such that the virtuous see only the salient fact and nothing else. Rather, it is a matter of taking in the situation as a whole and focusing on what is important so that other considerations which, in other circumstances, might constitute reasons for acting in certain ways, fail to do so in the present situation. McDowell is explicit that the 
virtuous need not-and, indeed, often cannot-be blind to situational features, even if they do not take those features to be salient. The courageous, for instance, are not blind to the risks involved when they decide to stand and fight. Likewise, the temperate are not ignorant of the deliciousness of the chocolate cake they pass up. Yet in their respective views of the situations, these features-the risks and the deliciousness - are not salient.

For the virtuous, when faced with a situation in which there is a clear requirement of virtue, their knowledge of how one ought to live combines with their knowledge of the particulars of the situation to produce a view in which one fact about the situation is seen as salient. It is the reliable arrival at this single salient fact that, McDowell insists, is distinctive of the virtuous. He highlights that distinctiveness by contrasting the virtuous person's view of a situation with that of the vicious, on the one hand, and of those who act continently and incontinently on the other. As we shall see, the singularity of this salient fact at which the virtuous arrive accounts both for the distinction between the virtuous and those who act continently and incontinently, and for the absence of internal conflict on the part of the virtuous.

These contrasts between the virtuous, the vicious, and those who act continently and incontinently make clear that, in one sense, the psychological picture that McDowell elaborates is meant to apply to individuals more generally. McDowell refuses to draw a sharp distinction between the intellectual and desiderative components of one's character, putting him at odds with what he calls the 'quasi-Humean' reading of Aristotle and with Humeans more generally. In upbringing, intellect and desire are shaped together (McDowell I998: 40) such that the individual becomes sensitive-both cognitively and motivationally-to certain sorts of reasons for acting (McDowell I998: 58). This is consistent with the Aristotelian view that we are all shaped by the activities that we repeatedly do such that we come to possess a character of one sort or another (Nicomachean Ethics: II.I). For those of us who are not fully virtuous, the shortcomings in our moral outlooks mean that we do not qualify as having the kind of knowledge that the virtuous do in this regard. Our moral outlooks, however, still combine with knowledge of the particulars of the situation as they do in the case of the virtuous. The crucial difference is that we fail to arrive reliably at the salient fact as the virtuous do.

The vicious person sees no reason at all to be virtuous; she has, therefore, a considerably different conception of how to live than the virtuous person does. As a result, her view of a particular situation will be significantly different from the way a virtuous person would see it (McDowell I998: 80). As an example, say that a man walking down the sidewalk has unwittingly dropped a hundred-dollar bill. A virtuous person walking behind him sees that he dropped his money and that she can return it to him, which she does. Contrast this with a vicious person: she sees an opportunity to pocket the bill and continue on her merry way one hundred dollars richer, which she does. Both women in this example seem to have the same knowledge of the particulars of the situation, yet the way in which this knowledge combines with their conceptions of how to live yields widely differing views of the situation: one sees an occasion to help while the other sees an 
occasion for self-enrichment. Anyone who doubts the degree to which these two see the situation differently need only to propose to one the other's course of action. The likely response would be: 'Why in the world would $I$ do that?'

Unlike the vicious, those who act continently and incontinently do not respond to the prospect of acting as the virtuous act with, 'Why in the world would I do that?' Although the person who acts continently successfully fights an inclination to keep the money and the person who acts incontinently gives in and pockets it, they both acknowledge that they ought to return the money. They seem, then, to see the situation in the same way that the virtuous person does. But this, McDowell insists, is not quite right: although-unlike the vicious-there is an extent to which those who act continently and incontinently share the virtuous person's conception of the situation, their views are at best approximations (I998: 47).

The key to grasping the difference between the views of the virtuous on the one hand and those who act continently and incontinently on the other, McDowell argues, is to understand that, for all of them, the formation of the judgment that they ought to return the money is not the result of a process of weighing reasons for and against particular courses of action. According to McDowell, the virtuous person does not consider competing reasons for action. She does not weigh reasons to return the money against reasons to keep it, with the former winning out. Rather, she focuses on the fact that the man failed to realize that he had dropped his money. For the virtuous, nothing else about the situation-such as the fact that she could pocket the money without anyone noticing-matters. Any considerations that could serve as reasons to do something other than return the money are, in McDowell's language, 'silenced' (I998: 56), that is, they fail to operate as reasons in the individual's practical reasoning. The feature upon which the virtuous person focuses-that the man failed to realize that he had dropped his money-engages with one of her concerns, say, her concern for other people's property, and this yields the action that she performs, namely picking up the money and returning it to its owner.

In judging what they ought to do, those who act continently and incontinently do not weigh reasons, either, according to McDowell; however, things unfold differently for them (I998: 47). Like the virtuous, they take the fact that the man failed to realize that he had dropped his money as important. Their conceptions of how one ought to live are similar enough to that of the virtuous that they recognize that this is all that they should take as important. This allows them to form the judgment that they ought to return the money (or, perhaps better: that the virtuous thing to do would be to return the money). But they do not have the kind of focus that the virtuous do. Their conception of how one ought to live differs from the virtuous, such that their focus extends to other features of the situation as well, like the fact that the man dropped a hundred-dollar bill, or that no one would notice if they picked it up and put it in their pocket. In other words, we do not get the silencing that we do with the virtuous, which is why their views of the situation are blurry or clouded, as McDowell says (I998: 92). Because these other features are in focus as well, concerns other than the one for other people's property-say, how pleasurable it is to spend money-are likely to be engaged. And this results in the internal struggle experienced by those who act continently 
and incontinently that is absent in the virtuous. The struggle comes, according to McDowell, not from weighing reasons for and against a course of action, but rather from multiple desires that have become engaged due to a lack of focus (I998: 92).

The silencing view, then, is offered explicitly as an alternative to the overriding view. McDowell contends that the overriding view falls short in two ways. First, it fails to preserve Aristotle's distinction between acting continently and acting from virtue (McDowell I998: 55). On the overriding view, both those who act from virtue and those who act continently would consider reasons to keep the money, reasons that would be more or less promptly overridden by reasons to return it. There would be no way, McDowell argues, to account for why those who act continently experience and must overcome desires to act contrary to virtue while those who act from virtue do not. If reasons to act contrary to virtue exert motivational force on those who act continently, why would they not do the same on the virtuous? Any difference between acting continently and acting from virtue would simply be a matter of degree.

Furthermore, McDowell contends, the overriding view looks unable to account for the internal conflict experienced by those who act continently and incontinently (McDowell I998: 92-93). Take the person who acts incontinently in our example: she judges that she ought to return the money. If she weighed reasons for and against keeping the money in order to arrive at that judgment, then her reasons to keep the money are overridden by reasons to return it. Moreover, McDowell points out, the motivational force of the reasons to keep the money would be used up, so to speak, in that process of weighing. Yet she goes against her judgment and keeps the money. How, McDowell wonders, could reasons to keep the money possibly continue to exert motivational force on her after she has weighed her various reasons and arrived at the judgment that she ought to return the money? Any motivation to keep the money would also seem to be motivation to revise the judgment to return it. But those who act incontinently do not doubt their judgment regarding what they ought to do. Since those who act continently also experience desires to act contrary to virtue despite their judgment of what ought to be done, the same question would apply to them as well.

If there is to be a meaningful distinction between acting from virtue and acting continently, and if we are to make sense of the conflict experienced by those who act continently and incontinently, then there has to be an alternative to the overriding view. McDowell provides such an alternative: considerations that might serve as reasons in favor of acting contrary to virtue are not taken into account in arriving at the virtuous person's view of the situation (McDowell I998: 93). Their motivational force, therefore, does not get used up as it would if one were to weigh reasons. But since those considerations are silenced for the virtuous individual, they fail to exert any motivational force on her. Those who act continently and incontinently, however, do not experience such silencing. This means that they can experience the motivational force of these considerations. This allows multiple concerns of theirs to be engaged simultaneously, resulting in internal struggle. 
Before moving on, let me emphasize the narrowness of scope that McDowell grants silencing (I998: 5 I, 53n5, 93). He commits only to the claim that the virtuous reliably experience silencing in situations where there is a clear requirement of virtue. There will be, one imagines, situations in which there is no clear requirement of virtue. The silencing view does not entail that the virtuous cannot or do not weigh reasons for and against various courses of action in such situations. I return to this question of scope later.

\section{Criticisms of the Silencing View}

Several philosophers have found the silencing view straightforwardly implausible. For example, Daniel Jacobson asserts against McDowell that the idea of the individual weighing reasons 'is surely more plausible' (2005: 402). Simon Blackburn complains that the notion of silencing-particularly the way in which the virtuous person is not so much as tempted to do otherwise-suggests a 'god-like nature' that 'belongs to nobody, and represents an ideal to which nobody can approximate' (I998: 37), a point echoed by Baxley (2007: 4II). Jeffrey Seidman also finds the silencing view implausible, at least in the vast majority of cases (2005).

We can see, then, a few distinct claims being lodged against the silencing view. First, there is skepticism regarding the existence of the psychological phenomenon of silencing. There is also the assertion that the more psychologically plausible view of practical reasoning is the overriding view, where the individual weighs reasons for and against various courses of action. Furthermore, there is the worry that McDowell's view is too idealistic, in the sense that it is inadequately buman.

One primary source of these objections to the silencing view is McDowell's insistence that nothing forgone for the sake of virtue constitutes a 'genuine loss' for the virtuous. For the virtuous, he says, 'no payoff from flouting a requirement of excellence ... can count as a genuine advantage; and, conversely, no sacrifice necessitated by the life of excellence . . can count as a genuine loss' (I998: I7). Sacrifice for the sake of virtue fails to constitute a genuine loss for McDowell because if a consideration is silenced, it fails to constitute a reason for action (I 7). If one forgoes something which one had no reason to secure, then passing up that thing cannot, McDowell contends, count as a loss (I8). This is so even if the thing forgone is a good that one would have reason to secure in other circumstances. We can see, then, how the notions of silencing and genuine loss go together: if considerations are silenced in the way that McDowell claims, then forgoing the goods that those considerations would otherwise have us pursue cannot register as a loss for the virtuous individual in her practical reasoning because if she registers a loss, then the consideration was not actually silenced.

Many have found McDowell's claims about loss unpalatably Stoic, even some who are otherwise sympathetic toward the silencing view (e.g., Hursthouse I999: I 82-83, Swanton 2003: 88-89). Seidman gives an example of a shopkeeper faced with bankruptcy, whose only remaining options to prevent losing the business that supports his family involve acting dishonestly: 
[I]f we accept that the shopkeeper would not take the loss of his business to be a genuine loss, we render his previous deliberative efforts unintelligible. If losing the business would not matter to him, why has he struggled so mightily to keep it afloat? One could avoid this difficulty by supposing that when it turns out that there is no morally acceptable way of keeping his business, the shopkeeper suddenly ceases to regard losing it as a genuine loss. But this view is hardly tenable. It is true, of course, that he will recognize that he could avoid the loss of his business only by acting dishonestly - and so enduring a different, and worse, sort of loss. But the lesser of two losses is still a loss. (2005: 73)

How could it be, the objection goes, that the sacrifice of a life's project, or one's health, say, could fail to constitute a loss? This would require a degree of detachment or insensitivity on the part of the virtuous that looks simply implausible for humans, if not downright undesirable. The objection contends that loss of life, health, loved ones, life projects, and so on are real losses because they are genuine goods that we generally have reason to pursue. One's reasons to maintain life and health cannot disappear simply because there is a worthy battle to be fought. It must be the case, according to this objection, that those reasons are not silenced, but rather overridden by weightier concerns.

\section{Genuine Loss and the Phenomenon of Silencing}

While the Stoicism running through McDowell's comments about loss is undeniable, I do not think his claim that something forgone for the sake of virtue cannot constitute a genuine loss for the virtuous is as stark as his language and his critics sometimes suggest. The silencing view does not deny that things like life, health, or loved ones are, in fact, goods or that we have, in many cases, reason to pursue those goods. In attempting to understand the practical reasoning of the virtuous, however, McDowell insists that one must recognize that there are multiple dimensions of worthwhileness, and the concept of eudaimonia-the ancient Greek notion of happiness or flourishing-marks out just one of those dimensions, although, crucially, the virtuous recognize it as the dimension of 'worthwhileness par excellence' (I998: 4I-43). Aristotle distinguishes among dimensions of worthwhileness in the Nicomachean Ethics when he outlines three objects of pursuit ('pursuit' is Myles Burnyeat's [1999] translation of hairesis; cf. Irwin's [1999] 'choice'): the fine or noble (kalon), the expedient, and the pleasant (I I ${ }_{4} \mathrm{~b}_{3} \mathrm{O}$ ). The virtuous person is, of course, concerned first and foremost with the fine or noble, which is why that dimension of worthwhileness reigns supreme. McDowell elaborates:

The relevant dimension of worthwhileness is such that, if a consideration that belongs to it bears on a practical predicament, anyone who has learned to appreciate such considerations will see that nothing else matters for the question what shape his life should take here and now, 
even if the upshot is a life that is less desirable along other dimensions. (I998: 43)

This passage suggests that the silencing view can allow Seidman's shopkeeper to recognize that closing the store will result in a life that is less desirable along one dimension of worthwhileness. But that dimension of worthwhileness is not the one marked out by eudaimonia. Thus, when it comes to whether or not to act dishonestly, the fact that he might have to close the store does not matter to the virtuous shopkeeper. It fails to constitute a reason for acting.

Here we see another way in which the phenomenon of silencing ought to be understood as quite narrow in scope. Considerations are silenced in one's practical reasoning. To return to his comment on genuine loss, McDowell explains:

[I]f someone really embraces a specific conception of human excellence, however grounded, then that will of itself equip him to understand special employments of the typical notions of 'prudential' reasoningthe notions of benefit, advantage, harm, loss, and so forth-according to which (for instance) no payoff from flouting a requirement of excellence ... can count as a genuine advantage; and, conversely, no sacrifice necessitated by the life of excellence . . . can count as a genuine loss. (I998: I6-I7)

McDowell is not concerned here with the concepts of loss, harm, advantage, and benefit in general, but specifically in their employment in an individual's reasoning about what to do. In embracing virtue-including that specific and, of course, correct conception of human excellence-the virtuous come to use these terms in a special way in their practical reasoning. McDowell provides an example of such a special employment in a discussion of courage: 'taking harm to be, by definition, what one has reason to avoid, we can see . . . that no harm can come to one by acting thus [i.e., courageously]' (I998: 92). If, by definition, harm-and, presumably, loss-are things to be avoided, then of course no consequence of virtuous action can count as a harm or loss for the virtuous in their practical reasoning.

One might still object to McDowell's use of 'loss' here; I do not aim to defend it. My point is that his claim that no sacrifice necessitated by virtue constitutes a genuine loss does not look nearly as stark as that language might suggest. Rather, it seems to be the claim that the consequences of virtuous actions-insofar as their desirability, or lack thereof, falls along other dimensions of worthwhileness than the one marked out by eudaimonia-do not, for the virtuous, count as reasons to act contrary to virtue.

I therefore offer what I take to be the appropriate response to the example of the shopkeeper on behalf of the silencing view: The potential closing of the store does not count against acting honestly in the virtuous shopkeeper's reasoning about what to do. If the shopkeeper is indeed virtuous, then his decision is not between acting honestly and closing the store, on the one hand, and acting dishonestly and saving the store on the other. The only option is to act honestly; there is no reason to act 
otherwise than honestly. Likewise, there is no reason to avoid acting honestly. In the special McDowellian sense of to-be-avoided, therefore, the potential closing of the store does not count as a loss, understood in this narrow way.

None of this entails, however, that, as Seidman claims, the closing of the business would not matter at all to the shopkeeper. It is just, given the circumstances, not something to be avoided. But that does not mean that the closing of the store cannot or should not be acknowledged in other ways. The silencing view in no way entails that the virtuous cannot mourn or feel frustration (in an appropriate manner and to an appropriate degree). The shopkeeper's life is now less desirable along one dimension of worthwhileness; the silencing view gives us no reason to think that he cannot acknowledge that fact. Proponents of the silencing view, therefore, can agree with Seidman that something would be amiss if the shopkeeper had no affective response whatsoever to the closing of the store. Indeed, the closing of the store seems to provide a good reason to mourn. But note two things: (I) the prospect of mourning for the store does not constitute a reason for the virtuous shopkeeper to act dishonestly in order to keep the store, and (2) the mourning is not evidence that the shopkeeper acknowledges a reason to act otherwise than he did.

Furthermore, no part of the silencing view prevents the shopkeeper from feeling frustration if appropriate to the circumstances in which he closes the store. Of course, since he is virtuous, the shopkeeper will not feel frustration that the circumstances necessitated his acting honestly (see Hursthouse I999: 76-77). He may, however, feel frustration toward the circumstances in which he finds himself. He may be frustrated by the economic recession, the gentrification of the neighborhood, the corrupt land developer, or whatever it was that put him in a position to have to close the store-although here, too, this frustration would not constitute a reason for the shopkeeper to act otherwise than he did. We can see, then, that there is space for genuine affective responses to, and acknowledgment of, the fact that life is now less desirable along certain dimensions of worthwhileness, though not the dimension that matters most. This means that, on the silencing view, we should not expect a virtuous individual to be as detached or unfeeling as its critics have suggested.

Regarding skepticism about the actual occurrence of silencing, I suspect that one source of the skepticism stems from excessive focus on the virtuous. If we only think of silencing in relation to a virtuous person's practical reasoning, it is easy to conceive of silencing itself as a psychological phenomenon that is exclusive to the virtuous. Thus conceived, silencing would seem rather implausible: How can there be this special psychological phenomenon that only the virtuous experience? If silencing were particular to the virtuous, virtuous practical reasoning would seem less like excellent human reasoning, and more like something altogether different.

Recall, however, two points from above: (I) the McDowellian account of practical reasoning is meant to apply to individuals more generally; and (2) McDowell commits only to the claim that the virtuous reliably experience silencing in situations where there is a clear requirement of virtue. Nothing in the silencing view suggests that the psychological phenomenon of silencing itself is exclusive to the virtuous. Indeed, it seems quite unlikely to be. Although there is 
considerable debate regarding the psychology of the vicious (see, e.g., Roochnik 2007; Müller 20I5; Elliott 20I6), one could imagine a thoroughly vicious individual seeing at least some situations with the kind of clarity of focus ascribed to the virtuous-for example, seeing the case of the dropped money as an opportunity for self-enrichment, as discussed earlier. Moreover, some of us may experience silencing in certain situations or with regard to certain considerations despite our being less than fully virtuous. On the silencing view, what is distinctive about the virtuous is that they reliably experience silencing in situations where there is a clear requirement of virtue, in a way that allows them to get things right (see McDowell I998: 5I). While none of this establishes the existence of the phenomenon of silencing, it does suggest that the phenomenon itself need not be particularly special or rare. As I argue below, there is a psychologically plausible way of understanding the phenomenon of silencing through which the kind of reliable silencing experienced by the virtuous can be seen as an excellence of decidedly human practical reasoning.

\section{Salience as Subjective Construal}

Even if one accepts that the above criticisms of the silencing view are misplaced, there remains the question of how we are to understand this 'salient fact' that the virtuous individual comes to recognize in her view of a situation where there is a clear requirement of virtue. Although McDowell consistently says that the virtuous person focuses on a single salient fact about the situation at hand (e.g., I998: 55$56,69)$, it is difficult to say what, exactly, this salient fact is supposed to be. This is a critical lacuna in the McDowellian account. That the virtuous focus on the salient fact in a given situation and, moreover, that this salient fact is singular, is crucial to the silencing view. That they take only one fact to be salient is what distinguishes the virtuous from those who act continently and incontinently; it also explains the lack of internal conflict on the part of the virtuous. Furthermore, it is this salient fact that silences all reasons to act contrary to virtue. Without a clear account of what this salient fact is supposed to be, however, one cannot properly assess the plausibility of the silencing view.

Some of the possible ways of understanding salience suggested by McDowell's own language are unsatisfactory. For instance, McDowell sometimes seems to suggest that the salient fact just is a feature of the situation (e.g., I998: 46-47), but this would be problematic. It may be plausible that in certain, exceedingly straightforward circumstances—such as, perhaps, our dropped money examplethere is only one feature on which the virtuous focus. In complex social situations, however, it seems likely that multiple situational features will be important to the virtuous. Moreover, a feature of a situation is not yet a reason for (a particular) action and, on its own, can serve both virtuous and nonvirtuous behavior. For instance, 'It was the truth' may be a reason to be honest (I take these reasons, which are offered as characteristic of particular virtues, from Hursthouse [1999: I28]). But imagine a politician being confronted by a reporter who has pictures of the politician engaging in illicit activities. Here, 'It was the truth' might be a reason to lie in the face of (true) accusations. Similarly, 'I owe it to her' may be a 
reason to be just, or it may be a reason for me-quite unjustly — to avoid letting my sister see the wad of cash that is in my wallet. 'Someone had to volunteer' may be a reason to step forward courageously or to cower in the back corner. What is distinctive of the virtuous is that they take certain features as reasons for particular sorts of responses to the situation at hand. If a particular feature of a situation can serve both virtuous and nonvirtuous behavior, the salient fact at which the virtuous arrive must be something other than the feature itself.

In other places McDowell seems to suggest that the salient fact is the 'thing to be done' (e.g., I998: 9I). In that case, the salient fact in the dropped money example would be something like, 'Return the money'. But thinking of the salient fact in this way cannot be right, since on the silencing view the salient fact engages a concern and this engagement yields action. By the time one arrives at 'Return the money', however, the relevant concern has surely already been engaged. 'Return the money' does not engage my concern for other people's property; rather, it is the engagement of my concern that yields the thing to be done.

I propose an interpretation of 'salience' that avoids the above problems: salience, I argue, should be understood in terms of subjective construal. I should be clear that this is not an attempt at interpreting McDowell; I remain unsure as to how he understands salience. Rather, I offer this interpretation of salience as a way of defending the plausibility of the silencing view. Understanding salience as subjective construal, I contend, offers a psychologically plausible way of understanding both silencing and the internal struggles of those who act continently and incontinently. Moreover, it leaves the McDowellian explanation of why there are these differences between the virtuous and those who act continently and incontinently-namely, that there are important differences in their moral outlooks resulting from differences in their habituation-intact.

In trying to understand an individual's response to a particular situation, psychologists recognize the importance of the ways in which individuals subjectively construe situations. In short, an individual's interpretation of a situation is a crucial determinant of her response to that situation. For example, it would be difficult to make sense of the behavior of gang members without reference to the ways in which they construe situations as demanding a demonstration of loyalty to their gang. An individual's subjective construal of a situation is one kind of a more general psychological phenomenon known as encoding.

'Encoding' can refer to both the process through which an individual organizes stimulus input into meaningful units and the construal at which the individual arrives as a result of that process. The construal can be thought of as a label, brief but informative (Ross and Nisbett I99I: 76). Encoding involves selective attention, interpretation, and categorization (Mischel I973: 267-68). Regarding selective attention, an individual pays more attention to certain features of a situation than others, and the features to which different individuals selectively attend vary. As an example, some individuals might focus on the shape of a particular cookie, whereas others may focus on its taste. Individuals also vary in how they interpret and categorize features of situations. One might categorize a coworker as a peer or as a rival; one might interpret a pat on the shoulder as 
supportive or intimidating. In addition to encoding individual features of a situation, one also encodes the situation as a whole; this particular encoding is often referred to as a subjective construal. By selectively attending to particular features of a situation, and then interpreting and categorizing those features, an individual forms a subjective construal of that situation.

Which features are attended to, as well as how those features are interpreted and/ or categorized, depends upon the schemas available and accessible to the individual doing the encoding (Mischel, Shoda, and Ayduk 2008: 382-83). Schemas are the mental representations individuals use to interpret and categorize the world around them. They often have a prototype structure, grouping together particular examples of a concept based upon similarities between examples, with some of these examples better exemplifying the concept than others (Mischel, Shoda, and Ayduk 2008: 380 ). For instance, an apple is a more prototypical fruit than a tomato.

Whether or not a particular schema is engaged in a particular situation depends upon its availability, accessibility, and applicability (Higgins I996: I34-35). A schema is available to an individual if that individual has the schema in her memory. For example, every person on the planet probably has an available schema for 'insect'. Members of uncontacted tribes in South America presumably will not have an available schema for 'smartphone'. Accessibility refers to the ease with which an available schema can be engaged. A more easily accessible schema may be activated via free recall, whereas a less easily accessible schema might only be engaged via cued recall. The probability that a schema will be engaged also depends upon its applicability to the situation. The more similarities between the schema and the attended features of the situation, the greater the applicability of the schema. With increased applicability comes the increased likelihood that the schema will be activated.

Note that the similarities between schema and situation involved in applicability concern attended features. As mentioned above, individuals selectively attend to some features of situations and not others. We might attend to some features of a situation because of properties of the situation itself. For example, I am likely to attend to the one red marble in a bag of blue marbles because it is the only red marble. But schemas direct our attention, too, and once engaged, can affect to which features of a situation one attends (Mischel, Shoda, and Ayduk 2008: 38 I82). I may pay more attention to the red marble in a bag of multi-colored marbles, for instance, because red is my favorite color. This attention-directing aspect of schemas is significant because one's conception of how one ought to live is itself a complex, cognitive-affective schema (see Mischel, Shoda, and Ayduk 2008: 38485 ). This means that it can direct an individual's attention and therefore affect that individual's subjective construals of situations.

The virtuous have a particular set of stably interrelated schemas that are available and easily accessible, namely those involved in their conception of how one ought to live. These would include what constitutes a good life, what it means to be kind or fair or generous, what kinds of things are worth going in for, and so on. These schemas affect not only how the virtuous categorize particular features of situations, but also to which features of situations the virtuous attend. The virtuous use these schemas to encode the various features of the situations that 
they encounter and to form subjective construals of those situations. A vicious person, by contrast, has a markedly different moral outlook and so has available and accessible a considerably different set of schemas. When facing the same situation as a virtuous person, the vicious person's attention is directed by those schemas in different ways than the virtuous and, furthermore, the vicious person interprets and categorizes the attended features according to those different schemas. As a result, where a virtuous person sees a situation demanding a virtuous response, the vicious person sees no such thing.

I contend that, for the virtuous faced with a situation where there is a clear requirement of virtue, there is only one applicable schema for construing the situation; that single subjective construal is the salient fact at which they arrive. Return once more to the example of the dropped money. As discussed earlier, our virtuous individual construes the situation as an occasion to help. Why does she not construe the situation as an occasion for self-enrichment, as the vicious person does? Because taking things that belong to other people has absolutely no place in her schemas regarding how things are acquired, and so she does not experience a match between the attended features of the situation (the dropped money) and her schema 'occasion for self-enrichment'. This is not to say that she must be so naive as to fail to recognize that other, less scrupulous individuals view taking other people's property to be a perfectly good means of acquisition. The claim is just that such a view does not apply to her.

The way in which one construes a situation plays a large part in determining what reasons one takes oneself to have and for what. Consider, for example, individuals whose deep-seated fear of rejection has rendered them what psychologists call 'rejection sensitive' (Downey and Feldman I996). These individuals are always on the lookout for potential signs that they are about to be rejected by a partner. As a result, they tend to perceive rejection in what are otherwise ambiguous situations. This perceived rejection then tends to generate hostile behavior (Ayduk et al. I999). In other words, because these individuals construe an ambiguous situation as one of rejection, they take themselves to have reason to be hostile and so that is how they act.

Similarly, our virtuous individual's construal of the dropped money situation as an occasion to help plays a large part in determining what the situational feature of the dropped money serves as a reason for. Namely, it is a reason for her to return the money. Contrast that with the vicious individual who thinks that taking other people's property is a perfectly good means of acquisition and so construes the situation as an occasion for self-enrichment. For her, that very same situational feature of the dropped money will serve as a different reason, namely, to keep the money. Construed as an occasion to help, the dropped money cannot serve as a reason to keep the money; construed as an occasion for self-enrichment, the dropped money cannot serve as a reason to return the money. In this way, we can think of 'occasion to help' and 'occasion for self-enrichment' as competing construals of the situation.

Whereas the virtuous individual feels only the attraction of the construal 'occasion to help' and the vicious person is attracted only to the construal 'occasion for self-enrichment', those who act continently and incontinently, I want 
to suggest, feel the attraction of both of these competing construals. These individuals share, to varying extents, the virtuous person's conception of how one ought to live. Unlike the vicious, they largely accept that a life of virtue is the best kind of life that one can live. They hold, as the vicious do not, that it is good to be kind, generous, and honest, that it is wrong to be dishonest, and so on. And they generally agree with the virtuous as to what constitutes kindness, generosity, and so on. So although they do not have available and accessible the exact set of schemas that the virtuous do, it seems reasonable to expect that the schemas they do have available will exhibit a considerable amount of overlap with those of the virtuous. Presumably, the schemas that constitute this overlap will direct their attention in much the same way as they direct the virtuous person's. To the extent that they share schemas with the virtuous, then, those who act continently and incontinently are likely to attend to the same features that the virtuous do and to categorize and interpret those features in the same way that the virtuous do.

Of course, their commitment to this kind of moral outlook is not as thorough-going as that of the virtuous and so the schemas available and accessible to those who act continently and incontinently are not a complete match with the virtuous person's. For instance, unlike the virtuous, it may not be the case for those who act continently and incontinently in the dropped money example that taking things that belong to other people has absolutely no place in their schemas regarding how things are acquired. Even a marginal role for this means of acquisition may be enough to allow them to feel the attraction of the construal 'occasion for self-enrichment'.

What accounts for these differences in schemas? Here I offer the same Aristotelian answer that McDowell does: differences in moral outlooks stem from differences in habituation and education. Part of what habituation entails, then, is developing the correct schemas.

This last point highlights the notion of 'subjective' that is in use here. A construal is subjective because it depends upon the psychology of the individual; it is a grasp of the situation from that person's perspective. It is not the case, however, that the correctness of the construal is wholly determined by, say, the attitude of the individual doing the construing; I do not mean for subjective construal to be subjective in that sense. McDowell, following Aristotle, is adamant that the virtuous get things right; my interpretation of salience as subjective construal is likewise committed to the idea that, at least in situations where there is a clear requirement of virtue, there will be a correct way to construe the situation.

\section{Implications of the Account}

Understanding salience as subjective construal has several important implications. For one, it retains the idea that reasons to act contrary to virtue are silenced for the virtuous. In singularly construing the situation as an opportunity to help, our virtuous individual does not take herself to have any reason to keep the money. Reasons to keep the money are therefore silenced, we could say, in her practical reasoning. There are, then, no reasons to act contrary to virtue to be outweighed or overridden because the only reasons that she takes herself to have are reasons 
to return the money. Note, too, that the ways in which the virtuous might affectively acknowledge silenced considerations that I argue for earlier in this article would still apply.

In addition, we can see that, contrary to Seidman's claim, the silencing view can render intelligible the deliberative efforts of the shopkeeper. Why did the shopkeeper work so hard to keep the business afloat? Because it was a good life project that he had good reason to pursue, so long as he could do so virtuously. But the desirability, or lack thereof, of the consequences of virtuous actions do not constitute reasons to act contrary to virtue. We can, for instance, imagine the shopkeeper sincerely thinking, 'I did everything that I could to keep the store going', where failing to report cash sales on his tax return, while something that might have allowed him to keep the store, was simply not on the table, so to speak, as an available option (thanks to Jesse Prinz for this example). Such a practice has no place in the shopkeeper's schemas regarding how one ought to run a business.

Moreover, understanding salience as subjective construal preserves the distinction between acting from virtue and acting continently, and accounts for the internal struggles of those who act continently and incontinently. The virtuous acknowledge only one applicable (virtuous) schema for subjectively construing a situation where there is a clear requirement of virtue. Those who act continently and incontinently, by contrast, feel the attraction of multiple subjective construals. Their inner conflict comes not from weighing reasons, but from competing construals. Each construal gives the individual access to a different set of reasons (or, perhaps, reasons to do different things), but note: that individual only gets access to those reasons via the construal. When the situation is construed as an occasion to help, then the dropped money can serve as a reason to return it to its owner. When the situation is construed as an occasion for self-enrichment, then the dropped money can serve as a reason to keep it. The tension experienced by those who act continently and incontinently, then, is between whether this is an occasion to help or an occasion for self-enrichment. It is a question of how they are going to make sense of the situation at hand, of which features of the situation will serve as reasons, and of what those features will serve as reasons for. And as we have seen, elaborating this internal struggle in terms of competing construals allows for significantly more precision in describing what is at issue than does reliance on McDowell's metaphors of blurry or clouded focus (I998: 92).

We are still left with the question: What accounts for the difference between those who act continently and those who act incontinently-that is, between those who return the money despite wanting to keep it and those who pocket the money, knowing they should not? Since his primary concern is to offer a view of practical reasoning that can account for the internal struggle experienced by both those who act continently and those who act incontinently, McDowell does not provide us with an answer to this question. The difference is found, I suspect, in the extent to which they dwell on the competing construals as well as the extent to which the engaged concerns are central to them. My suggestion is that the relevant schemas of the person who acts continently are closer to those of the virtuous than are those of the person who acts incontinently. Thus, they may direct her attention such that she can resist the nonvirtuous competing construal in a way that the 
person who acts incontinently cannot. Likewise, the relevant virtuous concerns may figure more centrally in her conception of how one should live than they do for the person who acts incontinently, allowing her to resist the nonvirtuous construal. Their opting for one construal or the other, then, stems from differences in their moral outlooks, not differences in the amount of weight they assign to a particular reason.

Regarding the differences between those who act continently and those who act incontinently, I want to keep it an open question the extent to which continence and incontinence are settled states of character. Here, I think, is a good place to take up McDowell's suggestion that '[i]t helps to make this idea of a flawed approximation to practical wisdom intelligible if we take continence and incontinence to characterize people who are on their way to acquiring virtue' (I998: 48-49). The development of virtue across domains is uneven at best; each individual will have her strengths and weaknesses. The view I have elaborated here allows for the possibility that one may act continently in some kinds of situations and incontinently in others. Thinking about those who act continently and incontinently from a developmental perspective also reminds us of the ways in which our different moral outlooks and characters-and, likewise, our differences in abilities to resist nonvirtuous construals or not-stem from differences in our habituation, which is itself a process that is continually ongoing (I I 80a I- 3 ).

One might worry that this account suggests that those who act incontinently fail to act for reasons at all, for it might look as though they are simply overwhelmed by, say, nonrational, appetitive desire. In opting for the nonvirtuous construal, however, the individual gains access to a set of reasons for which she acts. The person who acts incontinently pockets the money because the man dropped it, and no one would notice if she just took it, and acquiring and spending money is so very pleasurable. So even though her cognitive and affective schemas are directing her attention such that she opts for the nonvirtuous construal, the person who acts incontinently is still very much acting for reasons. In this case, she knows perfectly well why she did what she did-the dropped money, no one noticing, and so on-and, furthermore, she realizes, even if only implicitly, that taking those features of the situation to be reasons to pocket the money reflects poorly on her character.

\section{A Human Ideal of Practical Reasoning}

The view that I have developed here offers a substantive reply to the critics of silencing. First, the psychological phenomenon of silencing itself is likely not exclusive to the virtuous. What is distinctive of the virtuous is reliably experiencing silencing in situations where there is a clear requirement of virtue. Furthermore, given the narrowness of scope granted to silencing, there looks to be significant space for acknowledgement of and affective responses to the consequences of virtuous actions, even if those considerations are silenced in one's practical reasoning. Understanding salience as subjective construal can account for both the distinction between acting from virtue and acting continently as well as the internal conflict of those who act continently and incontinently in a 
psychologically plausible way. What we have is not a god-like ideal, but rather a human one.

DENISE VIGANI

SETON HALL UNIVERSITY

DENISE.VIGANI@SHU.EDU

\section{References}

Aristotle. (I999) Nicomachean Ethics. Translated by Terence Irwin. 2nd ed. Indianapolis: Hackett. Ayduk, Ozlem, Geraldine Downey, Alessandra Testa, Ying Yen, and Yuichi Shoda. (I999) 'Does Rejection Elicit Hostility in Rejection Sensitive Women?' Social Cognition, I7, 245-7I.

Baxley, Anne Margaret. (2007) 'The Price of Virtue'. Pacific Philosophical Quarterly, 88, 403-23.

Blackburn, Simon. (1998) Ruling Passions: A Theory of Practical Reasoning. Oxford: Clarendon Press.

Burnyeat, M. F. (I999) 'Aristotle on Learning to be Good'. In Nancy Sherman (ed.), Aristotle's Ethics: Critical Essays (Lanham, MD: Rowman \& Littlefield), 205-30.

Downey, Geraldine, and Scott I. Feldman. (I996) 'Implications of Rejection Sensitivity for Intimate Relationships'. Journal of Personality and Social Psychology, 70, I327-43.

Elliott, Jay R. (2OI 6) 'Reply to Müller: Aristotle on Vicious Choice'. British Journal of the History of Philosophy, 24, II93-I203.

Higgins, E. Tory. (I996) 'Knowledge Activation: Accessibility, Applicability, and Salience'. In E. Tory Higgins and Arie W. Kruglanski (eds.), Social Psychology: Handbook of Basic Principles (New York: Guilford Press), I33-68.

Hursthouse, Rosalind. (1999) On Virtue Ethics. Oxford: Oxford University Press.

Jacobson, Daniel. (2005) 'Seeing by Feeling: Virtues, Skills, and Moral Perception'. Ethical Theory and Moral Practice, 8, 387-409.

McDowell, John. (I998) Mind, Value, and Reality. Cambridge, MA: Harvard University Press.

Mischel, Walter. (I973) 'Toward a Cognitive Social Learning Reconceptualization of Personality'. Psychological Review, 80, 252-83.

Mischel, Walter, Yuichi Shoda, and Ozlem Ayduk. (2008) Introduction to Personality: Toward an Integrative Science of the Person. 8th ed. Hoboken, NJ: John Wiley \& Sons.

Müller, Jozef. (2015) 'Aristotle on Vice'. British Journal of the History of Philosophy, 23, 459-77.

Roochnik, David. (2007) 'Aristotle's Account of the Vicious: A Forgiveable Inconsistency'. History of Philosophy Quarterly, 24, 207-20.

Ross, Lee, and Richard Nisbett. (I99I) The Person and the Situation: Perspectives of Social Psychology. Philadelphia: Temple University Press.

Seidman, Jeffrey. (2005) 'Two Sides of “Silencing”'. Philosophical Quarterly, 55, 68-77.

Swanton, Christine. (2003) Virtue Ethics: A Pluralistic View. Oxford: Oxford University Press. 